\title{
Acute liver failure: An up-to-date approach ${ }^{2}$, 败谈
}

\section{Filipe S. Cardoso, MD MSc ${ }^{\text {a,*}}$, Paulo Marcelino, MD, PhD ${ }^{\text {a }}$, Luís Bagulho, MD ${ }^{\mathrm{a}}$, Constantine J. Karvellas, MD, SM ${ }^{\text {b }}$}

a Intensive Care Unit, Curry Cabral Hospital, Central Lisbon Hospital Center, Lisbon, Portugal

${ }^{\mathrm{b}}$ Divisions of Gastroenterology (Liver Unit) and Critical Care, University of Alberta Hospital, Edmonton, Canada

\section{A R T I C L E I N F O}

\section{Keywords:}

Hepatitis

Liver failure

Critical care

\begin{abstract}
A B S T R A C T
Acute liver failure is a rare but potentially devastating disease. Throughout the last few decades, acute liver failure outcomes have been improving in the context of the optimized overall management. This positive trend has been associated with the earlier recognition of this condition, the improvement of the intensive care unit management, and the developments in emergent liver transplantation. Accordingly, we aimed to review the current diagnostic and therapeutic approach to this syndrome, especially in the intensive care unit setting.
\end{abstract}

(c) 2017 Elsevier Inc. All rights reserved.

\section{Contents}

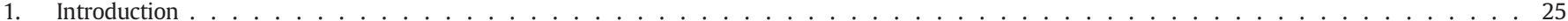

2. Definition and epidemiology $\ldots \ldots \ldots \ldots$

3. Pathophysiology and clinical manifestations . . . . . . . . . . . . . . . . . . . . . . . . . . . . . 26

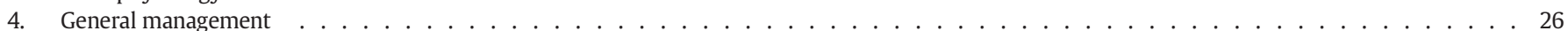

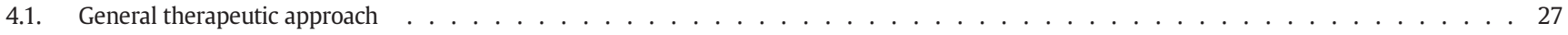

4.1.1. Hemodynamics . . . . . . . . . . . . . . . . . . . . . . . . . . . . . . . . . . . . . . 27

4.1.2. Hepatic encephalopathy . . . . . . . . . . . . . . . . . . . . . . . . . . . . 27

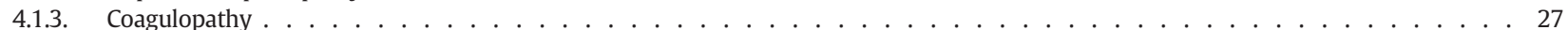

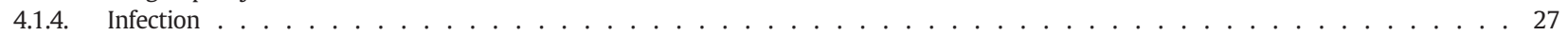

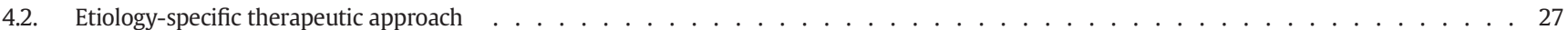

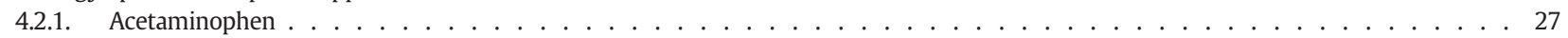

4.2.2. Non-acetaminophen . . . . . . . . . . . . . . . . . . . . . . . . . . . . . . . 28

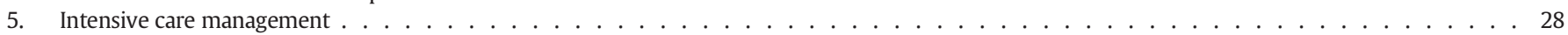

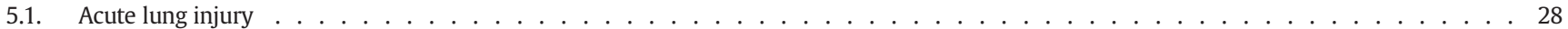

5.2. Hemodynamics . . . . . . . . . . . . . . . . . . . . . . . . . . . . . . . . 28

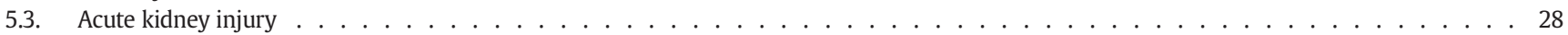

5.4. Cerebral edema and intracranial hypertension . . . . . . . . . . . . . . . . . . . . . . . . . . . . 28

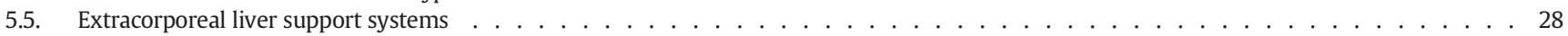

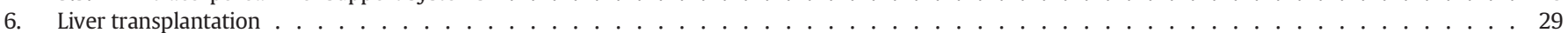

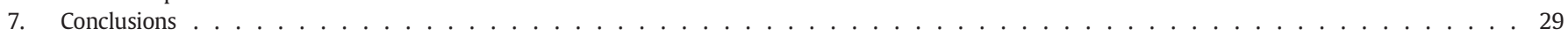

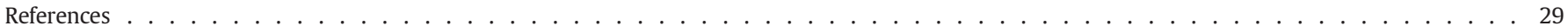

\footnotetext{
it Conflicts of interest: None.

故败 Funding: None.

* Corresponding author at: Polyvalent Intensive Care Unit, Curry Cabral Hospital, Central Lisbon Hospital Center, Rua da Beneficência, n. ${ }^{\circ}$ 8, 1069-166 Lisbon, Portugal. Tel.: +35121792 4200; fax: +351217924392.

E-mail address: filipe_sousacardoso@hotmail.com (F.S. Cardoso).
}

\section{Introduction}

Acute liver failure (ALF) is a rare condition characterized by new and rapidly evolving hepatic dysfunction associated with neurologic dysfunction and coagulopathy. It is more frequent in young individuals and its etiologies vary geographically, with impact on both clinical course and outcomes. Throughout the last decades, ALF outcomes have been improving in the context of the optimized overall management. However, its 
Table 1

ALF phenotypes

\begin{tabular}{|c|c|c|c|}
\hline & Hyperacute (within 7 d) & $\begin{array}{l}\text { Acute (8-28 } \\
\text { d) }\end{array}$ & Subacute (5-26 wk) \\
\hline Etiology example & Acetaminophen DILI, hepatitis A/E & Hepatitis B & Non-acetaminophen DILI \\
\hline Transaminases & +++ & ++ & + \\
\hline Bilirubin & + & ++ & +++ \\
\hline INR & +++ & ++ & + \\
\hline Cerebral edema & High risk & High risk & Low risk \\
\hline Survival without LT & High & Intermediate & Low \\
\hline
\end{tabular}

DILI indicates drug-induced liver injury.

present morbidity and mortality remain high in patients fulfilling poor prognostic criteria and without emergent liver transplantation (LT).

\section{Definition and epidemiology}

Acute liver failure definition has evolved throughout the time and presently includes the following features: international normalized ratio (INR) at least 1.5, neurologic dysfunction with any degree of hepatic encephalopathy (HE), no preexisting cirrhosis, and disease course of 26 weeks or less [1]. Exceptions to this definition may be patients with acute presentations of Wilson disease, autoimmune hepatitis, or vertically transmitted hepatitis B if by the time of the new hepatic insult, they also have underlying cirrhosis known for 26 weeks or less.

Acute liver failure has been subdivided into 3 phenotypes based on the time between jaundice and HE onset (Table 1): hyperacute (within 7 days), acute (8-28 days), or subacute (5-26 weeks) [2]. However, the clinical utility of this classification has not been entirely clarified because its impact on outcomes seems to be mostly associated with underlying etiologies [3].

Acute liver failure incidence has been reported as fewer than 10 cases per million people per year in developed countries [4]. Its etiologies vary worldwide: whereas in Eastern developing countries, viruses (mainly hepatitis A, B, or E) may account for up to 95\% of all ALF cases, the Western developed countries have reported more heterogeneous causes of ALF [5]. In the United Kingdom and the United States, acetaminophen overdose has been the leading cause of ALF [3,6]. In other parts of Europe (eg, Germany and Portugal), the most common causes of ALF have been non-acetaminophen drug-induced liver injury, seronegative (indeterminate) liver injury, and viruses (mostly hepatitis B) $[7,8]$. Acute liver failure etiologies are summarized in Table $2[1,3,4,9]$.

Acute liver failure outcomes have been improving throughout the decades with overall hospital survival increasing from 17\% in 1973 to

Table 2

ALF etiologies

\begin{tabular}{l}
\hline Viruses \\
Hepatitis A, B, D, or E viruses \\
Cytomegalovirus \\
Epstein-Barr virus \\
Herpes simplex virus \\
Varicella zoster virus \\
Parvovirus \\
Drug-induced liver injury \\
Acetaminophen \\
Non-acetaminophen (eg, isoniazid, phenytoin, valproate, propylthiouracil, \\
nitrofurantoin) \\
Recreational drugs (eg, cocaine, MDMA) \\
Autoimmune hepatitis \\
Ischemic/congestive hepatitis \\
Budd-Chiari syndrome \\
Wilson disease \\
Amanita phalloides \\
Pregnancy (eg, acute fatty liver of pregnancy, HELLP syndrome) \\
Heat stroke \\
Malignant infiltration \\
Seronegative (indeterminate)
\end{tabular}

Seronegative (indeterminate)
1978 to $62 \%$ in 2004 to 2008 in a single center from the United Kingdom [10]. In a multicenter registry from the United States in 1998 to 2010, ALF 2-year survival has been reported as 92\% for liver transplant (LT) recipients, $90 \%$ for acetaminophen overdose spontaneous survivors, and $76 \%$ for non-acetaminophen spontaneous survivors [11]. This positive trend has been attributed to the earlier recognition of this condition, the improvement of the intensive care unit (ICU) management, and the developments in emergent LT [10]. Overall, the most common causes of death in ALF have been multiorgan failure (18\%), liver failure (17\%), and sepsis (12\%) [11].

\section{Pathophysiology and clinical manifestations}

In ALF, the liver insult results in extensive death of hepatocytes with activation of the innate immune system responses (Kupffer cells and circulating monocytes) causing a large production of inflammatory mediators. The "spill-over" of these inflammatory mediators into the circulation ultimately leads to the systemic disturbances and clinical manifestations of ALF [12]. An overwhelming systemic inflammatory response syndrome (SIRS) is associated with the several organ failures that may ensue.

In parallel to the proinflammatory response, a compensatory antiinflammatory response develops [13]. Although within the injured liver, the production of anti-inflammatory mediators serves to dampen proinflammatory responses, limit the extent of tissue injury, and promote liver regeneration, their release into the systemic circulation is associated with a predisposition to infection [14]. At this stage, circulating monocytes may become functionally impaired and less able to respond to infectious stimuli, a state often referred as immune paresis $[15,16]$. Consequently, sepsis and multiorgan failure are frequently the cause of death in ALF. A summary of clinical manifestations related to the organ failures that may ensue in the context of ALF is presented in Table 3.

\section{General management}

The initial management of acute liver injury (hepatitis) or ALF is supportive with the objective to optimize conditions for the liver to

Table 3

ALF organ failures

\begin{tabular}{|c|c|}
\hline Organ failure & Pathophysiology \\
\hline Liver & $\begin{array}{l}\text { Hyperlactatemia: decreased lactate clearance } \\
\text { Hyperammonemia: decreased ammonia clearance } \\
\text { Coagulopathy: decreased synthesis of procoagulant and } \\
\text { anticoagulant factors } \\
\text { Hypoglycemia: decreased gluconeogenesis } \\
\text { Portal hypertension: may develop especially in subacute disease }\end{array}$ \\
\hline Brain & $\begin{array}{l}\text { HE: circulating inflammatory mediators and hyperammonemia } \\
\text { Cerebral edema: inflammatory mediators from microglial cells } \\
\text { and glutamine accumulation in astrocytes }\end{array}$ \\
\hline Cardiovascular & Hypotension or shock especially if sepsis superimposes \\
\hline Lungs & Acute lung injury or ARDS: SIRS, sepsis, and/or fluid overload \\
\hline Kidneys & AKI: SIRS, sepsis, and/or hypovolemia \\
\hline Pancreas & Acute pancreatitis: SIRS and/or drug toxicity (eg, acetaminophen) \\
\hline $\begin{array}{l}\text { Multi-organ } \\
\text { failure }\end{array}$ & SIRS or sepsis (immune paresis) \\
\hline
\end{tabular}


Table 4

Initial laboratory tests for acute liver injury or ALF

\begin{tabular}{ll}
\hline Assessment & Test \\
\hline Severity (serum) & Arterial blood gas \\
& Arterial lactate \\
& Arterial ammonia \\
& Hemoglobin, leukocytes, platelets \\
& INR, aPTT, fibrinogen, factor V \\
& AST, ALT, bilirubin, albumin, alkaline phosphatase, LDH, amylase \\
& Creatinine, urea, sodium, chloride, potassium, calcium, \\
& magnesium, phosphorus, creatine kinase \\
& HAV IgM, HBsAg, HBc IgM, anti-HCV, anti-HEV, CMV IgM, \\
Etiology & EBV IgM, HSV IgM, VZV IgM, anti-HIV \\
(serum or urine) & Ceruloplasmin, copper \\
& Anti-nuclear antibody, anti-smooth muscle antibody, \\
& immunoglobulins \\
& Acetaminophen, toxicology screen \\
& Blood type \\
& Pregnancy test (females)
\end{tabular}

aPTT indicates activated partial thromboplastin time; AST, asparte aminotransferase; ALT, alanine aminotransferase; LDH, lactate dehydrogenase; HAV, hepatitis A virus; HBs, hepatitis B virus surface antigen; $\mathrm{HBc}$, hepatitis B virus core antibody; $\mathrm{HCV}$, hepatitis $\mathrm{C}$ virus; HEV, hepatitis E virus; CMV, cytomegalovirus; EBV, Epstein-Barr virus; HSV, herpes simplex virus; VZV, varicella zoster virus; HIV, human immunodeficiency virus.

regenerate and prevent and treat as early as possible complications [17]. Although most patients with acute liver injury may be managed in a regular ward, patients with ALF should be referred to the ICU, ideally one in a center capable of providing emergent LT, as soon as possible as they may deteriorate quickly [1].

The initial diagnostic approach should be directed at detecting and assessing the severity of hepatitis, HE, coagulopathy, and other organ failures. Clinical history taking, if possible, may be important to understand the time between jaundice and HE onset, etiology factors (eg, alcohol intake, viral infection, drugs, mushroom, or tisane ingestion), and suspected or known previous liver disease. Physical examination allows to detect signs of organ failures and should include a mental status evaluation (West-Haven criteria for overt $\mathrm{HE}$ and, if feasible, a neuropsychological test for covert HE) and a search for stigmata of chronic liver disease. A list of useful initial laboratory tests is displayed in Table 4. Abdominal imaging with ultrasonography (with Doppler studies) or computed tomographic (CT) scan (with intravenous contrast if safe) helps to exclude features of chronic liver disease and biliary, pancreatic, or other intraabdominal pathology that could be the origin or contribute to the liver failure. Liver biopsy (transcutaneous or transjugular) should be considered whenever the etiology remains unclear and histopathology information may help to change management decisions, including LT assessment.

\subsection{General therapeutic approach}

\subsubsection{Hemodynamics}

Patients with ALF are often volume depleted at presentation and require fluid resuscitation. As in many other hypovolemic syndromes, crystalloids should be the initial fluids of choice, with normal saline (sodium chloride $0.9 \%$ ) being the most frequently in use [17]. Nevertheless, it may be considered the use of a chloride-restrictive solution (eg, Plasma-
Lyte 148, Hartmann's solution) as it has been shown in patients with acute illness that it may decrease the risk of metabolic acidosis and acute kidney injury (AKI) $[18,19]$. In a non-ICU setting, some of the simplest parameters can be used as targets for the initial fluid replenishment (while avoiding fluid overload), for example, mean arterial pressure at least 60 to $65 \mathrm{~mm} \mathrm{Hg}$, urine output at least $0.5 \mathrm{~mL} \mathrm{~kg}^{-1} \mathrm{~h}^{-1}$, and lactate $2 \mathrm{mmol} / \mathrm{L}$ or less.

On the contrary, patients with congestive hepatitis (eg, heart failure) may be fluid overloaded and diuretics may help to improve liver function.

\subsubsection{Hepatic encephalopathy}

The correction of all factors that may contribute to the acute confusion (eg, dehydration, infection, serum ions derangements) is important for HE treatment. With this objective, sedative medications should be avoided, except in situations deemed necessary (eg, agitation, periendotracheal intubation for progressive HE). To exclude intracranial pathology, a CT scan needs to be considered. Regular oral or enteral feeding should be maintained whenever feasible [20]. Lactulose may add to these patients' transplant-free survival, but careful should be taken with possible abdominal distension [21]. L-Ornithine-L-aspartate has not shown benefit to neither HE grade nor overall survival [22].

\subsubsection{Coagulopathy}

In ALF, overall hemostasis as measured by thromboelastography has been shown to be normal by several compensatory mechanisms, even in patients with markedly elevated INR [23]. In the absence of active bleeding or invasive procedure, it is not advisable to correct the INR with fresh-frozen plasma, because clinically significant blood loss is rare and correction obscures trends in the INR, an important marker of prognosis [1]. Nevertheless, vitamin K deficiency may be present in a minority of patients with ALF; thus, vitamin K supplementation may be used at least once $[1,24]$.

In ALF, bleeding due to fibrinolysis has been found to be limited due to high levels of plasminogen activator inhibitor-1 [25]. In the absence of active bleeding or invasive procedure, the platelet count should be maintained at least above the appropriate spontaneous bleeding threshold.

\subsubsection{Infection}

Acute liver failure risk of immune paresis increases susceptibility to infection which may preclude emergent LT. Therefore, surveillance for infection (including chest radiography and periodic cultures of sputum, urine, and blood) should be undertaken, while maintaining a low threshold for starting antimicrobial therapy [1]. Prophylactic antimicrobials have not been proven to improve 21-day survival in ALF [26]. Nevertheless, the development of grade III-IV HE or SIRS has been associated with infection and worse outcomes [27,28].

\subsection{Etiology-specific therapeutic approach}

\subsubsection{Acetaminophen}

$\mathrm{N}$-acetylcysteine (NAC) has been largely used as an antidote for acetaminophen intoxication. Its mechanism of action has to do mainly with glutathione replenishment, a crucial molecule for acetaminophen detoxification in the liver $[29,30]$. In ALF, NAC use has been shown to

Table 5

NAC protocols in ALF

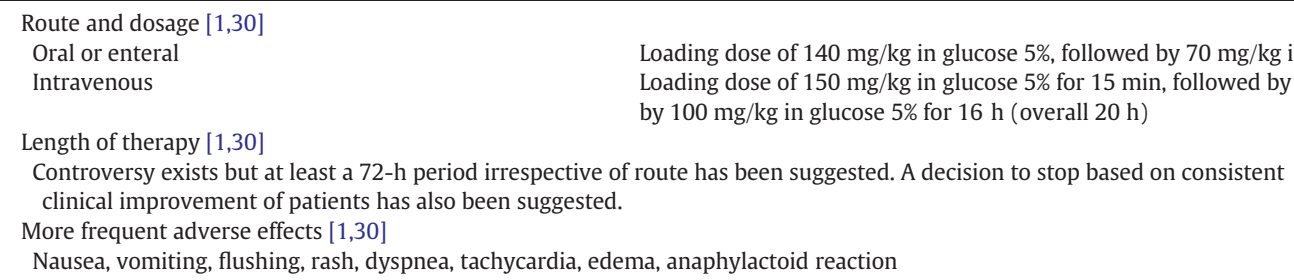


significantly improve overall survival with a low rate of adverse effects [31]. Although reported more effective within 48 hours of acetaminophen ingestion, NAC is currently being started in many centers when acetaminophen intoxication is suspected (eg, reported history of acetaminophen intake outside dose normal range or transaminases $\geq 3500$ $\mathrm{IU} / \mathrm{L}$, especially in an alcohol intake or fasting context), irrespective of acetaminophen dose, time since ingestion, or acetaminophen serum level because it is often difficult to establish when was the initial drug intake or if that was a one-time ingestion or a staggered overdose [1,32]. $\mathrm{N}$ acetylcysteine administration protocols are presented in Table 5.

\subsubsection{Non-acetaminophen}

In non-acetaminophen-related ALF, namely in drug-induced liver injury or hepatitis B, NAC seems to play a therapeutic role also as it has been shown to improve transplant-free survival when given during early HE stages (grade I-II) [33,34]. These results may be related to other effects that have been attributed to NAC, for example, improving hemodynamics and oxygen use and decreasing the risk of cerebral edema [26, 35]. The mechanism of such effects has not been cleared, but it may involve reducing the production of proinflammatory cytokines (eg, IL-17), scavenging of free radicals, or changes in the hepatic blood flow [35-37].

Several ALF etiologies may require specific therapies, for example: (1) consider antiviral therapy for hepatitis B virus, cytomegalovirus, herpes simplex virus, or varicella zoster virus-related ALF; (2) consider steroid therapy for autoimmune hepatitis-related ALF; (3) consider penicillin G or silibinin in Amanita phalloides-related ALF; and (4) consider emergent delivery for pregnancy-related ALF (eg, acute fatty liver of pregnancy or hemolysis, elevated liver enzymes, and low platelets [HELLP] syndrome) [1].

\section{Intensive care management}

Acute liver failure may lead to several organ failures; therefore, ICU admission should be considered as early as possible, especially when HE is being difficult to control in a regular ward or coagulopathy is progressing. In this context, supporting organ failures follows the rules of general ICU patients but with some specificities, which deserve to be emphasized.

\subsection{Acute lung injury}

Acute lung injury may occur in patients with ALF, more often at a later stage of their clinical course, namely with liver regeneration or sepsis [4]. Although patients with acute respiratory distress syndrome (ARDS) may require greater number of ventilator days, the requirement for vasopressors or renal replacement therapy (RRT), ICU stay, and mortality have been described as similar to patients without ARDS [38].

Management of ARDS in this context, albeit following general intensive care rules, may be more difficult because increasing positive endexpiratory pressure may exacerbate cerebral edema or liver congestion [39]. Nevertheless, finding the optimum positive end-expiratory pressure for each patient may help to improve oxygenation while minimizing such adverse consequences [40,41].

\subsection{Hemodynamics}

Patients with ALF typically present with a hyperdynamic circulation characterized by high cardiac output and low peripheral vascular resistance, a pattern resembling that of sepsis. For patients who continue to have hypotension despite volume repletion, noradrenaline is the preferred vasopressor, with or without adjunctive use of vasopressin or its analogs [42].

Echocardiography or invasive hemodynamic monitoring (eg, Pulse Contour Continuous Cardiac Output, Swan-Ganz catheter) should be used to assess cardiac function and help titrate decisions on the doses of fluids and/or vasopressors. Elevated troponin levels have been associated with an increase in grade III-IV HE and overall mortality [43].
Nevertheless, it is unclear whether that represents subclinical myocardial ischemia or simply reflects metabolic stress [44].

Relative adrenal insufficiency may be present and the use of steroids has been associated with a decrease in noradrenaline dose and overall mortality [45].

\subsection{Acute kidney injury}

Acute kidney injury may develop in up to $70 \%$ of patients with ALF and has been associated with worse overall survival [46]. Hyperphosphatemia develops with AKI if there is impaired liver regeneration and has been associated with poorer outcomes [47]. Acute kidney injury is often multifactorial and more common with certain etiologies: ischemic hepatitis, acute fatty liver of pregnancy, HELLP syndrome, heat stroke, hepatitis A virus, or drug-induced liver injury due to acetaminophen, phenytoin, trimethoprim-sulfamethoxazole, or macrolides [48].

In this context, classic indications for RRT initiation also apply, including severe acidosis, hyperkalemia, anuria, and/or fluid overload [49]. Further indications may include the following: removal of toxic substances (eg, acetaminophen, ammonia), difficult to treat hyponatremia, or difficult to treat hyperthermia [50,51]. Continuous modes of RRT are preferred over intermittent ones because the latter have been associated with increased risk of hemodynamic instability and cerebral edema [52].

\subsection{Cerebral edema and intracranial hypertension}

Cerebral edema incidence in patients with ALF has been decreasing throughout the last decades [10]. This positive trend may reflect improvements in the preventive care and use of emergent LT [17].

In ALF, astrocyte swelling may result in cytotoxic brain edema which may culminate in tonsillar herniation and death. Liver-brain proinflammatory signaling mechanisms involve the transduction of systemically derived cytokines as well as the gliotoxic effects of ammonia and lactate [53].

Frequent neurologic examination (including pupils) and the use of transcranial Doppler are simple strategies to monitor for signs of cerebral edema and intracranial pressure. On the contrary, CT findings compatible with intracranial hypertension often present too late in the course of this condition. Invasive monitoring of intracranial pressure has not been shown to improve these patients' hospital survival [54]. Nevertheless, it is still not clear if patients with the highest risk for cerebral edema and intracranial hypertension (eg, ammonia $>150 \mu \mathrm{mol} / \mathrm{l}$, vasopressors requirement, or RRT requirement) may benefit from such monitoring capacity [55].

The approach to cerebral edema and intracranial hypertension consists of the following: (1) head of the bed greater than $30^{\circ}$; (2) minimize patient stimulation; (3) sedation and invasive mechanical ventilation; (4) treat fever (although active hypothermia has not been proven to prevent cerebral edema and intracranial hypertension) [56,57]; (5) treat seizures (although prophylaxis has unclear value) [1]; (6) aim for a mean arterial pressure of at least $75 \mathrm{~mm} \mathrm{Hg}$ with fluids and/or vasopressors, with the goal being to maintain an intracranial pressure less than $25 \mathrm{~mm} \mathrm{Hg}$ and a cerebral perfusion pressure greater than $50 \mathrm{~mm} \mathrm{Hg}$; (7) consider using RRT to promote more effective ammonia clearance [51]; (8) aim for a serum sodium of 145 to $155 \mathrm{mmol} / \mathrm{L}$ with hypertonic saline (3\%-30\% infusion) for prophylaxis in patients with grade III-IV HE [58]; (9) consider using mannitol ( $0.5-1 \mathrm{~g} / \mathrm{kg}$ bolus) to transiently reduce intracranial pressure when there is established intracranial hypertension (repeat if serum osmolality $<320 \mathrm{mOsm} / \mathrm{L}$ ) [59]; and (10) consider using hyperventilation (aiming for a $\mathrm{PCO}_{2} 25-30 \mathrm{~mm} \mathrm{Hg}$ ) in cases of established intracranial hypertension despite optimized treatment to try to delay the progression to tonsillar herniation [60].

\subsection{Extracorporeal liver support systems}

The rationale for using an extracorporeal liver support (ECLS) system in ALF is to help maintain homeostasis while the liver regenerates (eg, 
Table 6

King's College criteria in ALF

\begin{tabular}{ll}
\hline Acetaminophen-related ALF & Non-acetaminophen-related ALF \\
\hline (A) Single criterion & (A) Single criterion \\
- pH $<7.30$ or lactate $>3.0 \mathrm{mmol} / \mathrm{L}$ & - INR $>6.5$ \\
after adequate fluid resuscitation & (B) 3 of 5 criteria \\
(B) 3 criteria & - Age $<10$ or $>40$ y \\
- Grade III-IV (West-Haven) HE & - Time from jaundice to coma $>7 \mathrm{~d}$ \\
- INR $>6.5$ & - INR $>3.5$ \\
- Creatinine $>3.4 \mathrm{mg} / \mathrm{dL}$ & - Bilirubin $>17 \mathrm{mg} / \mathrm{dL}$ \\
& - Unfavorable etiology: drug-induced \\
& liver injury, Wilson disease, or \\
& seronegative liver injury \\
\hline
\end{tabular}

ischemic hepatitis or acetaminophen-related ALF) or until an organ is available for transplantation (all etiologies). An ideal ECLS system would be one capable of assisting on 3 major liver functions: removal of toxins, biosynthesis, and immune modulation [61]. However, none of the artificial (depuration through membranes) or bioartificial (hepatocytes) systems available performs efficiently all of these functions $[62,63]$.

Two artificial ECLS systems have been studied in ALF with randomized controlled trials: molecular adsorbent recirculating system (MARS) and high-volume plasmapheresis (HVP). With MARS, blood is dialyzed across an albumin-impregnated high-flux dialysis membrane (pores with $50 \mathrm{kDa}$ ) and against a dialysate with albumin. Subsequently, 2 sequential adsorbent columns containing activated charcoal and anion exchange resin remove most of the water-soluble and albuminbound toxins. In a recent study, MARS has not been proven to improve 6-month survival in ALF [64]. However, a confounder may have been the median listing-to-transplant time which was only 16 hours, with $75 \%$ of enrolled patients undergoing LT within 24 hours.

With HVP, patients' plasma is replaced by fresh-frozen plasma with the objective of removing plasma cytokines and adhesion molecules, replacing plasma factors, and potentially modulating the immune system. In a recent study, HVP has been shown to significantly improve hospital survival, especially for patients with contraindications for LT [65]. Nevertheless, a limitation to account for may have been the 12-year inclusion period. With both MARS and HVP, adverse effects have been reported as similar to standard therapy [64,65].

Several bioartificial ECLS systems have been clinically tested, for example: HepatAssist (Arbios, formerly Circe, Waltham, Mass), ECLS device (ELAD; Vital Therapies, San Diego, Calif), modular ECLS system (MELS; Charité, Berlin, Germany), bioartificial liver support system (BLSS; Excorp Medical, Minneapolis, Minn), and Amsterdam Medical Center bioartificial liver (AMCBAL; AMC, Amsterdam, the Netherlands) [1]. A meta-analysis has shown that these systems failed to improve survival in ALF [66]. Nevertheless, more well-designed clinical trials in humans are likely needed to fully evaluate these systems efficacy and safety [67].

\section{Liver transplantation}

Liver transplantation is the only definitive treatment for patients with ALF. Overall survival after LT has been reported to be lower for patients with ALF in comparison to patients with cirrhosis until 1 year after transplant, but it tends to be similar from then on [68]. In fact, most deaths after LT for patients with ALF occur from infection during the first 3 postoperative months [4]. Nevertheless, survival after LT for ALF has been improving throughout the last decades, with 21-day survival reaching $96 \%$ for the period of 2006 to 2013 [69].

Cadaveric donor LT has been the norm in ALF, but living-donor transplant has been performed in some large-volume centers with acceptable outcomes. Despite this, controversy remains in regard to ethical issues, namely the risk of living-donor coercion and morbidity or mortality [70]. Another strategy to prevent waitlist mortality has been auxiliary transplantation (partial graft as temporary support for native liver regeneration), which has shown reasonable outcomes too [71].

In ALF, stratifying patients based on their risk of death without LT is crucial to prioritize them for transplantation. King's College criteria have been used worldwide for this purpose (Table 6) [72]. A recent metaanalysis has revealed its prognostic ability in comparison with the MELD score: for acetaminophen-related ALF, sensitivities were $58 \%$ and $80 \%$, respectively, and specificities were $89 \%$ and $53 \%$, respectively; for non-acetaminophen etiologies, sensitivities were $58 \%$ and $76 \%$, respectively, and specificities were $74 \%$ and $73 \%$, respectively [73]. Therefore, King's College criteria remain highly specific for acetaminophenrelated ALF, but less accurate for non-acetaminophen etiologies. Another useful tool for prognostication of death without LT in patients with hepatitis B-related ALF and grade III-IV HE may be the Clichy criteria. According to this tool, a serum factor $\mathrm{V}$ level lower than $20 \%$ in patients 30 years or younger or lower than $30 \%$ in any other patients prognosticates mortality with a positive predictive value of $82 \%$ and a negative predictive value of 98\% [74]. However, it has been shown that the Clichy criteria perform worse than the King's College criteria overall [75].

Risk stratification in ALF may be improved further if taking into account not only the probability of death without LT but also the probability of death after transplantation. Studies have suggested that some characteristics were associated with an increased risk of death after LT: male recipient, recipient older than 45 years, recipient on vasopressors, ABO-incompatible transplant, and high-risk graft use [76,77].

\section{Conclusions}

Acute liver failure diagnostic and therapeutic strategies have evolved throughout the time and that has been associated with improved outcomes. New advances in basic and clinical research may potentiate even more such outcomes. Despite this, these patients' early referral to an LT center, ICU timely treatment, and a comprehensive multidisciplinary strategy in risk stratification and selection for LT will continue to be fundamental steps for a successful approach.

\section{References}

[1] Lee W, Larson AM, Stravitz RT. AASLD position paper: the management of acute liver failure: update 2011. Available at: http://www.aasld.org/sites/default/files/guideline_documents/141022_Position_ALF_4UFb.pdf

[2] O'Grady JG, Schalm SW, Williams R. Acute liver failure: redefining the syndromes. Lancet 1993:342(8866):273-5.

[3] Ostapowicz G, Fontana RJ, Schiødt FV, Larson A, Davern T], Han SH, et al. Results of a prospective study of acute liver failure at 17 tertiary care centers in the United States. Ann Intern Med 2002;137(12):947-54.

[4] Bernal W, Wendon J. Acute liver failure. N Engl J Med 2013:369:2525-34.

[5] Acharya SK, Batra Y, Hazari S, Choudhury V, Panda SK, Dattagupta S. Etiopathogenesis of acute hepatic failure: Eastern versus Western countries. J Gastroenterol Hepatol 2002;17(Suppl. 3):S268-73.

[6] Gulmez SE, Larrey D, Pageaux GP, Bernuau J, Bissoli F, Horsmans Y, et al. Liver transplant associated with paracetamol overdose: results from the seven-country SALT study. Br J Clin Pharmacol 2015;80(3):599-606.

[7] Hadem J, Tacke F, Bruns T, Langgartner J, Strnad P, Denk GU, et al. Etiologies and outcomes of acute liver failure in Germany. Clin Gastroenterol Hepatol 2012;10(6): 664-9.

[8] Areia M, Romãozinho JM, Ferreira M, Amaro P, Leitão MC. Fulminant hepatic failure: a Portuguese experience. Eur J Gastroenterol Hepatol 2007;19(8):665-9.

[9] Bernal W, Auzinger G, Dhawan A, Wendon J. Acute liver failure. Lancet 2010; 376(9736):190-201.

[10] Bernal W, Hyyrylainen A, Gera A, Audimoolam VK, McPhail MJ, Auzinger G, et al. Lessons from look-back in acute liver failure? A single centre experience of 3300 patients. J Hepatol 2013;59(1):74-80.

[11] Fontana RJ, Ellerbe C, Durkalski VE, Rangnekar A, Reddy RK, Stravitz T, et al. Twoyear outcomes in initial survivors with acute liver failure: results from a prospective, multicentre study. Liver Int 2015;35(2):370-80.

[12] Possamai LA, Thursz MR, Wendon JA, Antoniades CG. Modulation of monocyte/macrophage function: a therapeutic strategy in the treatment of acute liver failure. J Hepatol 2014;61(2):439-45.

[13] Antoniades C, Berry P, Wendon J, Vergani D. The importance of immune dysfunction in determining outcome in acute liver failure. J Hepatol 2008;49:845-61. 
[14] Antoniades CG, Quaglia A, Taams LS, Mitry RR, Hussain M, Abeles R, et al. Source and characterization of hepatic macrophages in acetaminophen-induced acute liver failure in humans. Hepatology 2012;56:735-46.

[15] Antoniades CG, Khamri W, Abeles RD, Taams LS, Triantafyllou E, Possamai LA, et al. Secretory leukocyte protease inhibitor: a pivotal mediator of anti-inflammatory responses in acetaminophen induced acute liver failure. Hepatology 2014;59:1564-76.

[16] Antoniades CG, Berry PA, Davies ET, Hussain M, Bernal W, Vergani D, et al. Reduced monocyte HLA-DR expression: a novel biomarker of disease severity and outcome in acetaminophen-induced acute liver failure. Hepatology 2006;44:34-43.

[17] Bernal W, Lee WM, Wendon J, Larsen FS, Williams R. Acute liver failure: a curable disease by 2024? J Hepatol 2015;62(1 Suppl.):S112-20.

[18] Yunos MN, Bellomo R, Hegarty C, Story D, Ho L, Bailey M. Association between a chloride-liberal vs chloride-restrictive intravenous fluid administration strategy and kidney injury in critically ill adults. JAMA 2012;308(15):1566-72.

[19] Raghunathan K, Murray PT, Beattie WS, Lobo DN, Myburgh J, Sladen R, et al. Choice of fluid in acute illness: what should be given? An international consensus. Br J Anaesth 2014;113(5):772-83.

[20] Plauth M, Cabré E, Riggio O, Assis-Camilo M, Pirlich M, Kondrup J, et al. ESPEN guidelines on enteral nutrition: liver disease. Clin Nutr 2006;25(2):285-94.

[21] Alba L, Hay JE, Angulo P, Lee WM. Lactulose therapy in acute liver failure. J Hepatol 2002;36:33.

[22] Acharya SK, Bhatia V, Sreenivas V, Khanal S, Panda SK. Efficacy of L-ornithine L-aspartate in acute liver failure: a double-blind, randomized, placebo-controlled study. Gastroenterology 2009;136(7):2159-68.

[23] Stravitz RT, Lisman T, Luketic VA, Sterling RK, Puri P, Fuchs M, et al. Minimal effects of acute liver injury/acute liver failure on hemostasis as assessed by thromboelastography. J Hepatol 2012;56(1):129-36.

[24] Pereira SP, Rowbotham D, Fitt S, Shearer MJ, Wendon J, Williams R. Pharmacokinetics and efficacy of oral versus intravenous mixed-micellar phylloquinone (vitamin K1) in severe acute liver disease. J Hepatol 2005;42:365-70.

[25] Pernambuco JR, Langley PG, Hughes RD, Izumi S, Williams R. Activation of the fibrinolytic system in patients with fulminant liver failure. Hepatology 1993;18(6):1350-6.

[26] Karvellas CJ, Cavazos J, Battenhouse H, Durkalski V, Balko J, Sanders C, et al. Effects of antimicrobial prophylaxis and blood stream infections in patients with acute liver failure: a retrospective cohort study. Clin Gastroenterol Hepatol 2014;12(11):1942-9.

[27] Vaquero J, Polson J, Chung C, Helenowski I, Schiodt FV, Reisch J, et al. Infection and the progression of encephalopathy in acute liver failure. Gastroenterology 2003;125:755-64.

[28] Rolando N, Wade J, Davalos M, Wendon J, Philpott-Howard J, Williams R. The systemic inflammatory response syndrome in acute liver failure. Hepatology 2000;32:734-9.

[29] Saito C, Zwingmann C, Jaeschke H. Novel mechanisms of protection against acetaminophen hepatotoxicity in mice by glutathione and $\mathrm{N}$-acetylcysteine. Hepatology 2010;51(1):246-54.

[30] Heard K]. Acetylcysteine for acetaminophen poisoning. N Engl J Med 2008;359:285-92.

[31] Keays R, Harrison PM, Wendon JA, Forbes A, Gove C, Alexander GJ, et al. Intravenous acetylcysteine in paracetamol induced fulminant hepatic failure: a prospective controlled trial. BMJ 1991;303(6809):1026-9.

[32] Zimmerman HJ, Maddrey WC. Acetaminophen (paracetamol) hepatotoxicity with regular intake of alcohol: analysis of instances of therapeutic misadventure. Hepatology 1995;22(3):767-73.

[33] Singh S, Hynan LS, Lee WM, Acute Liver Failure Study Group. Improvements in hepatic serological biomarkers are associated with clinical benefit of intravenous $\mathrm{N}$ acetylcysteine in early stage non-acetaminophen acute liver failure. Dig Dis Sci 2013;58(5):1397-402.

[34] Lee WM, Hynan LS, Rossaro L, Fontana RJ, Stravitz RT, Larson AM, et al. Intravenous $\mathrm{N}$-acetylcysteine improves transplant-free survival in early stage nonacetaminophen acute liver failure. Gastroenterology 2009;137(3):856-64.

[35] Harrison PM, Wendon JA, Gimson AES, Alexander GJM, Williams R. Improvement by acetylcysteine of hemodynamics and oxygen transport in fulminant hepatic failure. N Engl J Med 1991;324:1852-7.

[36] Stravitz RT, Sanyal AJ, Reisch J, Bajaj JS, Mirshahi F, Cheng J, et al. Effects of $\mathrm{N}$ acetylcysteine on cytokines in non-acetaminophen acute liver failure: potential mechanism of improvement in transplant-free survival. Liver Int 2013;33(9):1324-31.

[37] Jones AL. Mechanism of action and value of $\mathrm{N}$-acetylcysteine in the treatment of early and late acetaminophen poisoning: a critical review. J Toxicol Clin Toxicol 1998;36:277-85.

[38] Audimoolam VK, McPhail MJ, Wendon JA, Willars C, Bernal W, Desal SR, et al. Lung injury and its prognostic significance in acute liver failure. Crit Care Med 2014; 42(3):592-600.

[39] Sass DA, Shakil AO. Fulminant hepatic failure. Liver Transpl 2005;11(6):594-605.

[40] Suter PM, Fairley B, Isenberg MD. Optimum end-expiratory airway pressure in patients with acute pulmonary failure. N Engl J Med 1975;292(6):284-9.

[41] Mascia L, Grasso S, Fiore T, Bruno F, Berardino M, Ducati A. Cerebro-pulmonary interactions during the application of low levels of positive end-expiratory pressure. Intensive Care Med 2005;31(3):373-9.

[42] Eefsen M, Dethloff T, Frederiksen H-J, Hauerberg J, Hansen BA, Larsen FS. Comparison of terlipressin and noradrenalin on cerebral perfusion, intracranial pressure and cerebral extracellular concentrations of lactate and pyruvate in patients with acute liver failure in need of inotropic support. J Hepatol 2007;47:381-6.

[43] Parekh NK, Hynan LS, De Lemos J, Lee WM, Acute Liver Failure Study Group. Elevated troponin I levels in acute liver failure: is myocardial injury an integral part of acute liver failure? Hepatology 2007;45(6):1489-95.

[44] Audimoolam VK, McPhail MJ, Sherwood R, Willars C, Bernal W, Wendon JA, et al. Elevated troponin I and its prognostic significance in acute liver failure. Crit Care 2012;16(6):R228.

[45] Marik PE, Gayowski T, Starzl TE, Hepatic Cortisol Research and Adrenal Pathophysiology Study Group. The hepatoadrenal syndrome: a common yet unrecognized clinical condition. Crit Care Med 2005;33(6):1254-9.
[46] Tujios SR, Hynan LS, Vazquez MA, Larson AM, Seremba E, Sanders CM, et al. Risk factors and outcomes of acute kidney injury in patients with acute liver failure. Clin Gastroenterol Hepatol 2015;13(2):352-9.

[47] Schmidt LE, Dalhoff K. Serum phosphate is an early predictor of outcome in severe acetaminophen-induced hepatotoxicity. Hepatology 2002;36:659-65.

[48] Urrunaga NH, Magder LS, Weir MR, Rockey DC, Mindikoglu AL. Prevalence, severity, and impact of renal dysfunction in acute liver failure on the US liver transplant waiting list. Dig Dis Sci 2016;61(1):309-16.

[49] Bagshaw SM, Wald R. Acute kidney injury: timing of renal replacement therapy in AKI. Nat Rev Nephrol 2016;12(8):445-6.

[50] Gosselin S, Juurlink DN, Kielstein JT, Ghannoum M, Lavergne V, Nolin TD, et al. Extracorporeal treatment for acetaminophen poisoning: recommendations from the EXTRIP workgroup. Clin Toxicol (Phila) 2014;52(8):856-67.

[51] Slack AJ, Auzinger G, Willars C, Dew T, Musto R, Corsilli D, et al. Ammonia clearance with haemofiltration in adults with liver disease. Liver Int 2014;34(1):42-8.

[52] Davenport A, Will EJ, Davidson AM. Improved cardiovascular stability during continuous modes of renal replacement therapy in critically ill patients with acute hepatic and renal failure. Crit Care Med 1993;21:328-38.

[53] Butterworth RF. Pathogenesis of hepatic encephalopathy and brain edema in acute liver failure. J Clin Exp Hepatol 2015;5:S96-S103.

[54] Karvellas CJ, Fix OK, Battenhouse H, Durkalski V, Sanders C, Lee WM, et al. Outcomes and complications of intracranial pressure monitoring in acute liver failure: a retrospective cohort study. Crit Care Med 2014;42(5):1157-67.

[55] Bernal W, Hall C, Karvellas CJ, Auzinger G, Sizer E, Wendon J. Arterial ammonia and clinical risk factors forEncephalopathy and intracranial hypertension in acute liver failure. Hepatology 2007;46(6):1844-52.

[56] Bernal W, Murphy N, Brown S, Whitehouse T, Bjerring PN, Hauerberg J, et al. A multicentre randomized controlled trial of moderate hypothermia to prevent intracranial hypertension in acute liver failure. J Hepatol 2016 [pii: S0168-8278(16)30030-7].

[57] Karvellas CJ, Todd Stravitz R, Battenhouse H, Lee WM, Schilsky ML, US Acute Liver Failure Study Group. Therapeutic hypothermia in acute liver failure: a multicenter retrospective cohort analysis. Liver Transpl 2015;21(1):4-12.

[58] Murphy N, Auzinger G, Bernal W, Wendon J. The effect of hypertonic sodium chloride on intracranial pressure in patients with acute liver failure. Hepatology 2002;39:464-70.

[59] Canalese J, Gimson AE, Davis C, Mellon PJ, Davis M, Williams R. Controlled trial of dexamethasone and mannitol for the cerebral oedema of fulminant hepatic failure. Gut 1982;23(7):625-9.

[60] Ede RJ, Gimson AE, Bihari D, Williams R. Controlled hyperventilation in the prevention of cerebral oedema in fulminant hepatic failure. J Hepatol 1986;2:43-51.

[61] Karvellas CJ, Subramanian RM. Current evidence for extracorporeal liver support systems in acute liver failure and acute-on-chronic liver failure. Crit Care Clin 2016;32(3):439-51.

[62] Khuroo MS, Khuroo MS, Farahat KL. Molecular adsorbent recirculating system for acute and acute-on-chronic liver failure: a meta-analysis. Liver Transpl 2004; 10(9):1099-106.

[63] Karvellas CJ, Gibney N, Kutsogiannis D, Wendon J, Bain VG. Bench-to-bedside review: current evidence for extracorporeal albumin dialysis systems in liver failure. Crit Care 2007;11(3):215

[64] Saliba F, Camus C, Durand F, Mathurin P, Letierce A, Delafosse B, et al. Albumin dialysis with a noncell artificial liver support device in patients with acute liver failure: a randomized, controlled trial. Ann Intern Med 2013;159(8):522-31.

[65] Larsen FS, Schmidt LE, Bernsmeier C, Rasmussen A, Isoniemi H, Patel VC, et al. Highvolume plasma exchange in patients with acute liver failure: an open randomised controlled trial. J Hepatol 2016;64(1):69-78.

[66] Kjaergard LL, Liu J, Als-Nielsen B, Gluud C. Artificial and bioartificial support systems for acute and acute-on-chronic liver failure: a systematic review. JAMA 2003; 289(2):217-22.

[67] Lee KC, Stadlbauer V, Jalan R. Extracorporeal liver support devices for listed patients. Liver Transpl 2016;22(6):839-48.

[68] Berg CL, Steffick DE, Edwards EB, Heimbach JK, Magee JC, Washburn WK, et al. Liver and intestine transplantation in the United States 1998-2007. Am J Transplant 2009; 9(4 Pt 2):907-31.

[69] Reuben A, Tillman H, Fontana RJ, Davern T, McGuire B, Stravitz RT, et al. Outcomes in adults with acute liver failure between 1998 and 2013: an observational cohort study. Ann Intern Med 2016;164(11):724-32.

[70] Brown Jr RS, Russo MW, Lai M, Shiffman ML, Richardson MC, Everhart JE, et al. A survey of liver transplantation from living adult donors in the United States. N Engl J Med 2003;348(9):818-25.

[71] van Hoek B, de Boer J, Boudjema K, Williams R, Corsmit O, Terpstra OT. Auxiliary versus orthotopic liver transplantation for acute liver failure. EURALT Study Group. European Auxiliary Liver Transplant Registry. J Hepatol 1999;30:699-705.

[72] O'Grady JG, Alexander GJM, Hayllar KM, Williams R. Early indicators of prognosis in fulminant hepatic failure. Gastroenterology 1989;97:439-55.

[73] McPhail MJ, Farne H, Senvar N, Wendon JA, Bernal W. Ability of King's College criteria and model for end-stage liver disease scores to predict mortality of patients with acute liver failure: a meta-analysis. Clin Gastroenterol Hepatol 2016;14(4):516-25.

[74] Bismuth SD, Gugenheim J, Castaing D, Bernuau J, Rueff B, et al. Emergency liver transplantation for fulminant hepatitis. Ann Intern Med 1987;107:337-41.

[75] Pauwels A, Mostefa-Kara N, Florent C, Lévy VG. Emergency liver transplantation for acute liver failure. Evaluation of London and Clichy criteria. J Hepatol 1993;17(1):124-7.

[76] Bernal W, Cross TJ, Auzinger G, Sizer E, Heneghan MA, Bowles M, et al. Outcome after wait-listing for emergency liver transplantation in acute liver failure: a single centre experience. J Hepatol 2009;50(2):306-13.

[77] Germani G, Theocharidou E, Adam R, Karam V, Wendon J, O'Grady J, et al. Liver transplantation for acute liver failure in Europe: outcomes over 20 years from the ELTR database. J Hepatol 2012;57(2):288-96. 